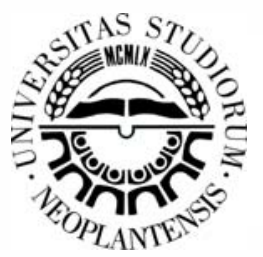

\title{
Experimental identitfication of essential features of micro strip drawing with double deflection
}

\author{
Lewin Rathmann, * Frank Vollertsen \\ Bremer Institut für angewandte Strahltechnik GmbH, Klagenfurter Str. 5, 28359 Bremen, Germany
}

\begin{abstract}
In sheet metal forming contact between blank and die edge is reduced to local contact zones. For micro range, they can easily be found during a simulation, but an experimental evidence is difficult.

Therefore, an optical projection of strip drawing with double deflection is presented and it is demonstrated that the contact zones can be identified using this method. These results are compared to those from simulation and it is shown that they reflect the simulative results. The results are presented on the basis of using a die with a die radius of $r=0.6 \mathrm{~mm}$. The height of the gap between die edge and blank at the moment of their maximum distance is determined in the experiment to $d=18 \pm 9 \mu \mathrm{m}$ while it is $d=2 \mu \mathrm{m}$ in the simulation.
\end{abstract}

Key words: Micro forming; friction; simulation.

\section{INIRODUCTION}

Due to the progressive miniaturization it is possible to transfer all the realised functions of a smartphone into a smart watch. This product moved up from a niche product of the consumer electronics to a product that is fullyintegrated in our everyday life. For example, the Apple Watch is the second biggest watch brand directly after Rolex [1].

So-called size effects in forming processes described, inter alia, by Engel in [2] are the reason why common knowledge in macro range cannot be transferred directly into micro range. For example, friction between die radius and flange of the blank determines the height of the required punch force. But, when lubricant is used it is also subjected to tribological size effects. That means that the smaller the geometrical dimensions of the experimental setup are chosen, the higher are the scaled punch force [3] and the friction coefficient [4]. An explanation for this behaviour is given by the lubricant pocket model in which the contact length plays a major role [5]. The contact length is the length of the contact zones which occur during the strip drawing process between blank and die radius. The geometrical values of the specimen are scaled with the geometrical dimensions of the tools.

The strip drawing test with double deflection is used to analyse the friction behaviour between blank and die radius. In 1980 Doege cited this test as one of the most important test methods to assess friction behaviour in deep drawing [6].

The advantage of strip drawing in comparison with deep drawing is the simplified state of stress in the flange of the blank: The tangential compressive stress in the flange is avoided making the strain conditions in the workpiece less complex during strip drawing. In 2004 Groche was able to prove that in macro range the surface pressure between blank and die radius is inhomogeneous over the edge of the radius [7]. The maximum pressure depends on increasing blank thickness, material strength and decreasing die radius. Hu could verify these studies in simulations of strip drawing with double deflection for the micro range and defined these zones of high pressure as local contact zones [8].

The length of these zones and its influence on the friction coefficient has to be investigated as a possibility to describe the tribological size effect according to the model of open and closed lubricant pockets [5]. Therefore, strip drawing with double deflection is simulated and its results are compared with those from the experiment.

*Corresponding author's.e-mail: rathmann@bias.de 


\section{METHODS}

\subsection{FE simulation}

The basic concept of the FE-simulation analysed with Abaqus v6-16 is a two-dimensional micro strip drawing FE-model of axial symmetric parts (Fig.1).

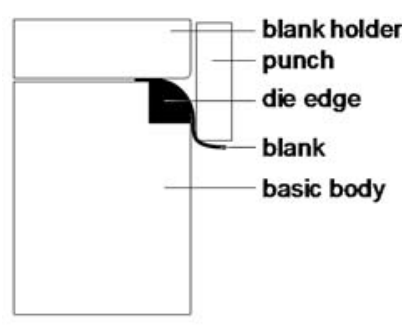

Rattmann 2017

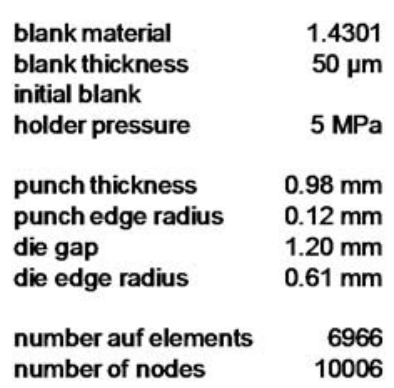

BAS D 181983
Fig. 1 Numerical setup of the two-dimensional strip drawing FE-model in Abaqus v6-16

The blank holder, the punch and the basic body of the die are defined as analytical rigid shells and therefore they are non-deformable and have no material properties. The die edge is simulated as deformable solid body with material properties. In the simulation it is made from tool steel 1.2379 (X155CrVMo12-1) and its properties are shown in Table 1.

Table 1 Values of the tool steel 1.2379 used in the simulation.

\begin{tabular}{|c|c|c|c|}
\hline Material & $\begin{array}{c}\text { Modulus of } \\
\text { elasticity E [GPa] }\end{array}$ & $\begin{array}{c}\text { Density } \boldsymbol{\rho} \\
{\left[\mathbf{g} / \mathbf{m m}^{\mathbf{3}}\right]}\end{array}$ & $\begin{array}{c}\text { Poisson } \\
\text { ratio } \boldsymbol{v}\end{array}$ \\
\hline 1.2379 & 210 & $7.91 \mathrm{E}-003$ & 0.33 \\
\hline
\end{tabular}

The tool geometries are measured ten times by a coordinate measuring machine, averaged and are shown in Fig. 1. The original tool topography is not considered. Instead an ideal smooth radius surface is used with averaged radius. The specimen is a rectangular blank and modelled as a deformable solid body with material properties as shown in Table 2.

Table 2 Values of the stainless steel 1.4301 used in the simulation as blank material.

\begin{tabular}{|c|c|c|c|}
\hline Material & $\begin{array}{c}\text { Modulus of } \\
\text { elasticity } \mathbf{E}[\mathbf{G P a}]\end{array}$ & $\begin{array}{c}\text { Density } \boldsymbol{\rho} \\
{\left[\mathbf{g} / \mathbf{m m}^{\mathbf{3}}\right]}\end{array}$ & $\begin{array}{c}\text { Poisson } \\
\text { ratio } \boldsymbol{v}\end{array}$ \\
\hline 1.4301 & 212,650 & $7.91 \mathrm{E}-003$ & 0.33 \\
\hline
\end{tabular}

It has five elements in thickness direction. Its elements as well as those of the die edge are made of CPS4R four node bilinear elements with reduced integration and hourglass control. Additionally, the symmetry axis of the die is utilized to reduce the model size and hence the computational effort. The used stress and strain curve describing the elastic-plastic behaviour of the blank during forming results from a tensile test with foils made of stainless steel 1.4301 with a thickness of $50 \mu \mathrm{m}$. It is necessary to convert this data into the true stresses and strains and to extrapolate it by Swift's law for stress and strain (see Eq. 1).

$$
\sigma_{\text {Swift }}=\sigma_{\text {true }, 0}\left(1+K \cdot \varepsilon_{\text {plastic }}\right)^{n}
$$

In this formula $\sigma_{\text {Swift }}$ represents the calculated stress, $\sigma_{\text {true, } 0}$ is the measured yield strength, while $K$ and $n$ are hardening parameters, which are manually modified. Table 3 gives an overview of the used parameters to model Swifts Law.

Table 3 Values of the stainless steel 1.4301 used in the simulation as blank material.

\begin{tabular}{|c|c|c|c|}
\hline Material & $\begin{array}{c}\text { Yield strength } \\
{[\mathbf{M P a}]}\end{array}$ & $\begin{array}{c}\text { Hardening } \\
\text { parameter } \boldsymbol{K}\end{array}$ & $\begin{array}{c}\text { Hardening } \\
\text { parameter } \boldsymbol{n}\end{array}$ \\
\hline 1.4301 & 390 & 14.7 & 0.5 \\
\hline
\end{tabular}

The extrapolation is necessary, because the material failure occurs in tensile test earlier than in strip drawing with double deflection due to the uniaxial load. Therefore, tensile test does not provide enough values for stress and strain curve used in the simulation. Fig. 2 shows the interpolated material data.

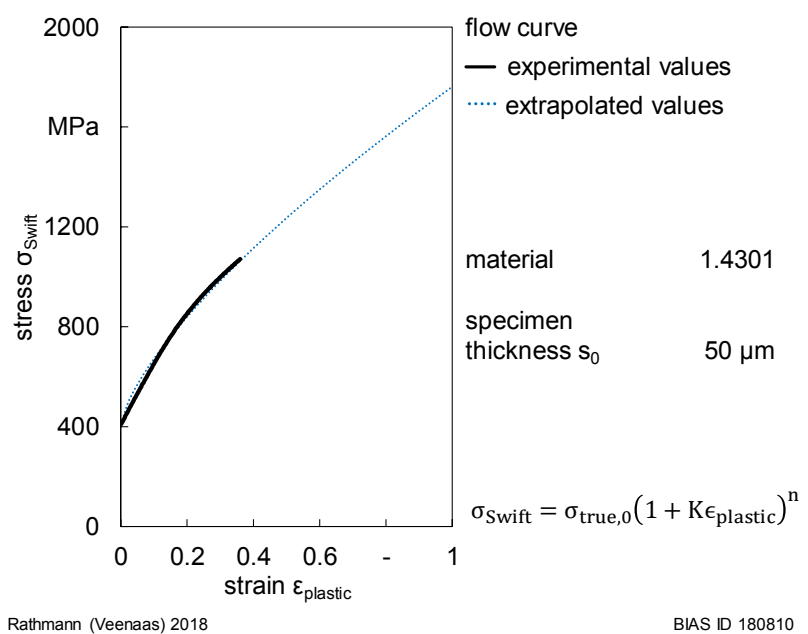

Fig.2 Comparison between experimental (black) and extrapolated (blue and dotted) flow curves

\subsection{Experimental setup}

Strip drawing experiments with three different drawing radii are carried out on a double-axis micro forming press, which is highly dynamic. A detailed technical description is provided in [9]. Each axis is driven by two electrical linear motors with a maximum acceleration of $10 \mathrm{~m} / \mathrm{s}^{2}$, a maximum velocity of $3.2 \mathrm{~m} / \mathrm{s}$ and achieving a positioning error lower than $3 \mu \mathrm{m}$ at maximum acceleration. The repeat positioning error of this press is below $1 \mu \mathrm{m}$ up to a stroke of $8 \mathrm{~mm}$. The two independent movable slides of the machine can be driven path- or force-controlled via feedback loop. In the experimental setup, a force measurement system with an accuracy of $0.01 \mathrm{~N}$ based on Kistler 9217A piezo load cells and a position measurement system based on Heidenhain LC481 linear scales with an accuracy of $3 \mu \mathrm{m}$ is included. The principle of the experimental setup is shown in Fig. 3 . 


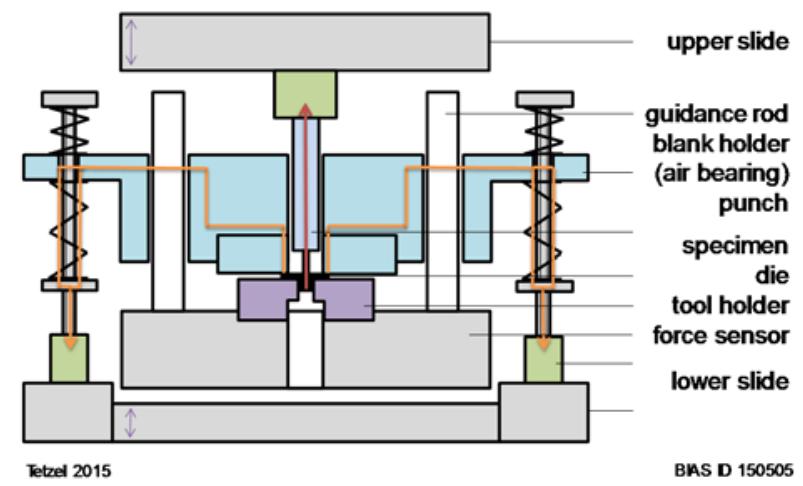

Fig. 3 Schematic sketch of the micro forming machine used for the experiments

The rectangular blanks are cut out of a steel strapping made of stainless steel 1.4301 (X5CrNi18-10) with a picosecond laser True Micro 5050 build by TRUMPF. The blanks have a thickness of $50 \mu \mathrm{m}$, a length of $4.5 \mathrm{~mm}$, a width of $1 \mathrm{~mm}$ and are placed on the die manually. No lubricant is used during the forming process, otherwise an identification of gaps between die radius and bottom side of the blank with the optical projection method would not be possible. Three dies are used with die radii of $r=0.110 \pm 0.002 \mathrm{~mm}$, $\mathrm{r}=0.294 \pm 0.005 \mathrm{~mm}$ and $\mathrm{r}=0.612 \pm 0.003 \mathrm{~mm}$. For each die ten blanks are drawn and each drawing process is documented with a camera. In case of the radii $\mathrm{r}=0.294 \mathrm{~mm}$ and $\mathrm{r}=0.612 \mathrm{~mm}$ the gap heights between die radius and bottom of the blank are determined for each drawing and each picture taken with the camera during the process.

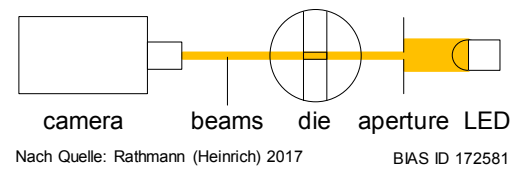

Fig. 4 Experimental setup for contact length measurement seen from above

A camera is placed on one side of the die taking pictures with a frame rate of $17 \mathrm{fps}$ of the strip drawing process. Its resolution is $1388 \times 1038$ at 1.4 Mpixels. It is equipped with a Sony ICX276 sensor with a $1 / 2$ CCD as sensor type. On the opposite side, a white light LED is placed. The visual axis of the camera, the drawing gab and the beams are aligning (Fig. 4). The gap height is measured with LabVIEW. The first step is pre-processing the image for contrast enhancement. After that a local threshold value is automatically set to get a binary image, that means that pixels above the threshold value will be white and pixels below the threshold value will be black. Then unwanted particles, so called noise, are removed from the image. A particle analysis function is used, that determines areas of each particle in the image. By selecting the area of the gap manually, a circle is drawn inside the gap with the biggest possible diameter. This diameter represents the gap height measured in pixels. To calibrate the gap measurement, the width of the die is determined to $d=1.205 \pm 0.006 \mathrm{~mm}$, while knowing that the number of pixels that cover this distance is $n=124$. Now, the width is divided by the number of pixels, resulting in the length of one pixel $1=0.009 \mathrm{~mm}$.

\section{RESULTS}

In Fig. 5 the strip drawing process in the experiment (above) and in the simulation (below) are compared. The first picture of the experiment displays the beginning of the process characterized by the initial contact between punch and blank $\left(\mathrm{s}_{\mathrm{p}}=0.0 \mathrm{~mm}\right)$ and the last pictures display the process at maximum punch displacement $\left(\mathrm{s}_{\mathrm{p}}=2.5 \mathrm{~mm}\right)$. The four pictures in between display an equidistant punch displacement of $\Delta \mathrm{s}_{\mathrm{p}}=0.5 \mathrm{~mm}$ and give an overview of the strip drawing process. It is shown that all characteristics of the simulation are found in the experiment: The gap between the punch bottom and the blank (Fig. 5, pictures 2-6), the upward displacement of the blank holder when the blank emerges under it (Fig. 5, picture 4) and finally the missing bending of the last part of the flange because of the missing pressure from the blank holder (Fig. 5, pictures 5 and 6).

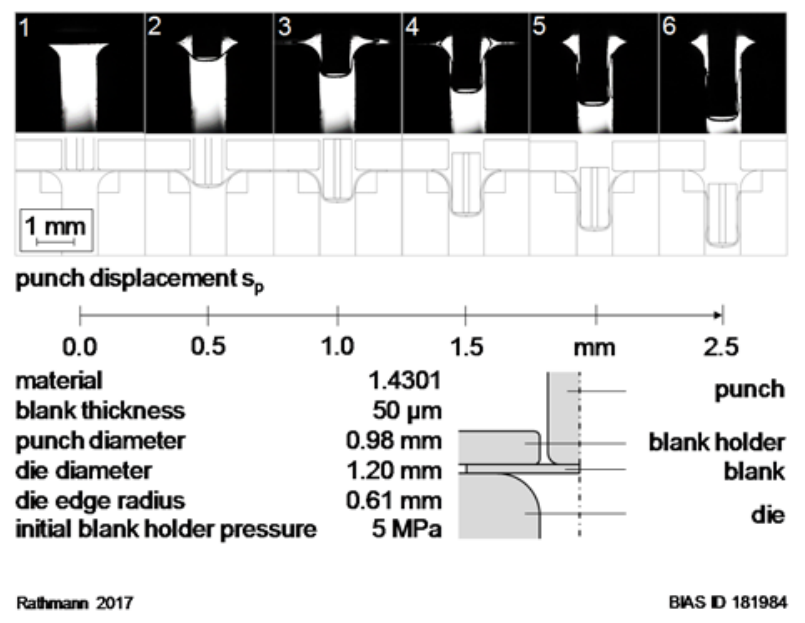

Fig. 5 Comparison between strip drawing in the experiment (above) and in simulation (below) at different punch displacements sp.

Fig. 6-a shows the experiment at a punch displacement of $\mathrm{s}_{\mathrm{p}}=0.81 \mathrm{~mm}$ and with a die radius of $\mathrm{r}=0.61 \mathrm{~mm}$. At this punch displacement the highest gap height was detected. It displays a gap between the die radii and the bottom side of the blank. This gap could also be found in the simulation at the same punch displacement (Fig. 6-b). The results of gap height measurements for three different die radii is shown in Fig. 7 as averaged values of gap heights from left and right die radius.

Using a die radius of $\mathrm{r}=0.11 \mathrm{~mm}$ no gap could be detected neither in the simulation nor in the experiment. But, using a die radius of $r=0.29 \mathrm{~mm}$ and $r=0.61 \mathrm{~mm}$, the gap was observed in the simulation as well as in the experiment. If the gap height that occurs at a die radius of $\mathrm{r}=0.61 \mathrm{~mm}$ is compared to that one occurring at a radius of $r=0.29 \mathrm{~mm}$, a ratio of $2: 1$ can be stated. This ratio is valid for both simulation and experiment. 


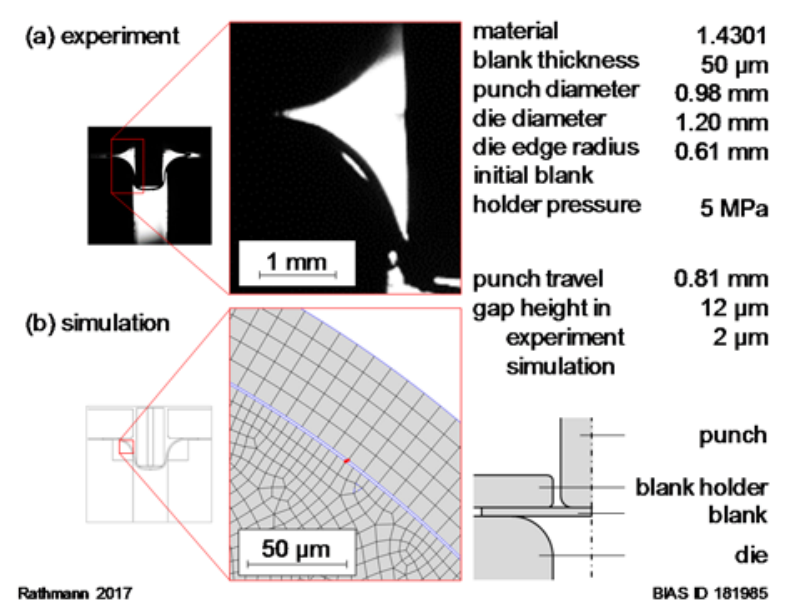

Fig. 6 Comparison between the gap in experimental strip drawing (a) and in simulation (b).
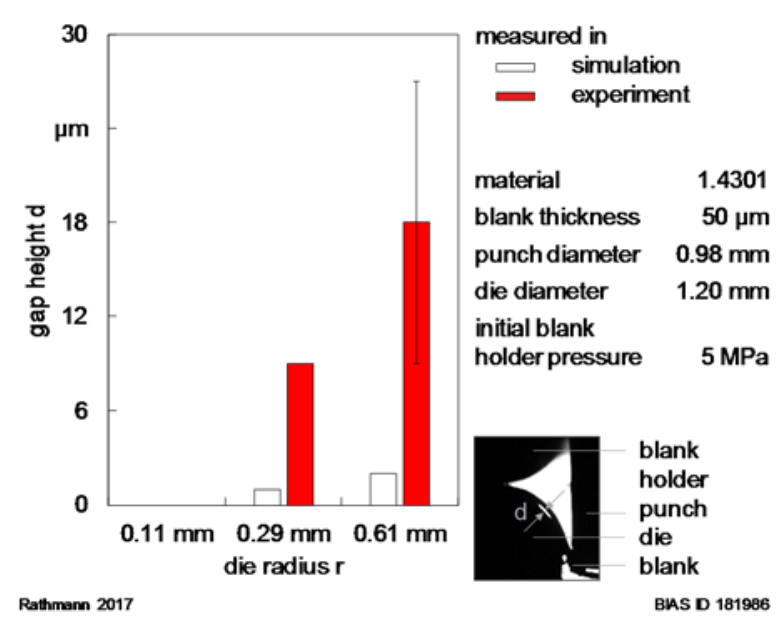

Fig. 7 Results of gap height measurement in simulation and experiment at different die radii.
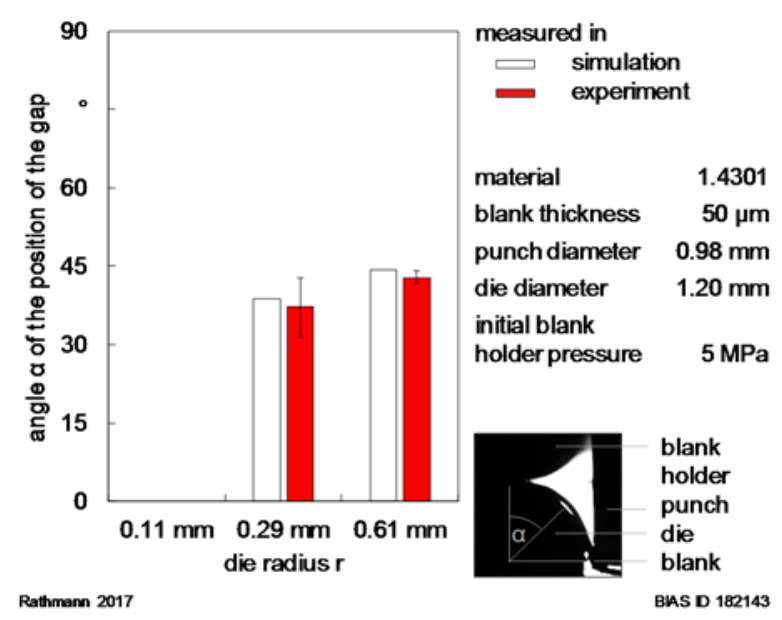

Fig. 8 Results of angle measurement to determine the position of the gap in simulation and experiment at different die radii.

Fig. 8 shows the results of the measurement of the angle $\alpha$ to determine the position of the gap on the die radius in simulation and experiment at different radii. An increase in the angle is observed, if the die radius is increased from $\mathrm{r}=0.29 \mathrm{~mm}$ to $\mathrm{r}=0.61 \mathrm{~mm}$. Due to missing gap, no angle was detected in case of a radius of $r=0.11 \mathrm{~mm}$. Simulation and experiment show similar results.

\section{Discussion}

The comparison between experimental and simulative results of strip drawing with double deflection demonstrate, that it is possible to display the characteristics of the simulation like the gap between the blank and the drawing radius in the experiment. Therefore, the experimental setup can be used to calibrate the simulation. Noticeable are the differences in the bending of the flange in the last third of the strip when it emerges under the blank holder and the slight tilting of the punch in the experiment (Fig. 5). The deviation in bending is traced to the material model used in the simulation (see Chapter 2.1 (1)) which is responsible for the forming behaviour of the blank. To receive the theoretical values for the stress and strain curve under inclusion of Swift's law, the constants $\mathrm{K}$ and $\mathrm{n}$ have to be varied until the theoretical stress and strain curve fits the experimental. Nevertheless, this numerical approximation of a real-world behaviour leads inevitably to differences in bending between simulation and experiment because of the limited representation accuracy of the varied constants $\mathrm{K}$ and $\mathrm{n}$. The slight tilting of the punch is a consequence of its positioning process. At first the die and the blank holder are aligned by alignment pins and fixed in their mounts. Then the punch is inserted through the blank holder into the die and is fixed on the upper slide. So, the slight tilting is either is a result of deviations in the positioning of the die and the blank holder or the fixation of the punch in its holder.

The results show that there are differences in the gap heights measured in simulation and experiment. As described in Chapter 2, averaged tool geometries are used in the simulation model. So, on the one hand there are perfect tool geometries with averaged geometry values used in the simulation and on the other hand there are the real tool geometries in the experiment with varying geometry values and surface topography. Additionally, the relative manufacturing tolerances cannot be scaled into micro range. The relative deviations from the nominal tool geometry, caused in tool manufacture, are increasing with decreasing size in the micro range because the accuracy of manufacturing reaches its limits [11]. So, it cannot be excluded that these deviations cause discrepancies in the gap heights.

Furthermore, the experimental setup has a big influence on the accuracy of gap measurement. Because of the spatial depth shadowing and reflections occur when the LED, the drawing gap and the light beams are not arranged coaxially. These phenomena lead to wrong numbers of bright pixels suggesting a bigger gap in case of reflection or a smaller gap in case of shadowing. In addition to that, light diffraction at the edges of the tools has an influence on this case too. 
Considering the tolerances, it can be said that the ratio of the gap heights for different die radii in the simulation and the experiment correspond as shown in Fig. 7. Additionally, the position of the appearing gap in the experiment is comparable to the position of the gap in the simulation for each die radius. Nevertheless, it can be seen that the essential features of the strip drawing process like the appearing gap and the gap position can be identified in principal and therefor the optical projection method proves to be feasible for the experimental identification of the contact zones and can be used for the validation of the FEM-Simulation.

\section{CONCLUSIONS}

An optical projection method to identify contact zones during strip drawing with double deflection in micro range was developed and is presented in this work. The comparison with the simulation show that the essential features of the strip drawing process like gap height and the position of the gap can be displayed. Additionally, the experiment can be used to calibrate the simulation. Finally, the development of the gap and its height between die radius and bottom side of the blank depends on the size of the die radius.

\section{ACKNOWFDGEMENTS}

This work has been funded by the Project Vo530/42-2 "Stempelgeschwindigkeit 2". The authors gratefully acknowledge the financial support by the Deutsche Forschungsgesellschaft.

\section{REFERENCES}

[1] Bitcom: Zukunft der Consumer Technology - 2017. URL: https://www.bitkom.org/Presse/Anhaenge-
an-PIs/2017/08-August/CT-Studie/170830-CTStudie-online.pdf. Last access: 19.06.2018

[2] Geiger M., Kleiner M., Eckstein R., Tiesler N. Engel U. (2001). Microforming. CIRP-Annals Manufacturing Technology 50, No. 2, pp. 445-462.

[3] Kals T. A., Eckstein R. (2000). Miniaturization in sheet metal working. Journal of Materials Processing Technology. 103, pp. 95-101.

[4] Engel U., Messner A., Tiesler N. (1998). Cold forging of microparts - effect of miniaturization on friction", in: J.L. Chenot et al (Eds.) Proceedings of the FIRST ESAFORM Conference on Materials Forming, 17-20 March'98, Sophia Antipolis, France, pp. 77-80.

[5] Engel U. (2006). Tribology in microforming. Wear. 260/3, pp. 265-273.

[6] Doege E., Witthüser K. P., Jost H. G. (1980) Prüfverfahren zur Beurteilung der Reibungsverhältnisse beim Tiefziehen, HFFBericht Nr.6, Hannover.

[7] Groche P., Filzek G. (2004). Local contact conditions in sheet metal forming and their simulation in laboratory test methods. Production Engineering. 10/1, pp.55-60.

[8] Hu Z., Vollertsen F. (2006). Tribological size effects in sheet metal forming measured by a strip drawing test. Annals of the CIRP. 55/1, pp. 291294.

[9] Schulze Niehoff H. (2008). Entwicklung einer hochdynamischen, zweifachwirkenden Mikroumformpresse. Strahltechnik Band 33, BIAS Verlag.

[10] Tetzel H. (2015). Influence of lubricant viscosity on punch force in strip drawing test", 4M/ICOMM,

[11] Behrens G., Trier F. O., Tetzel H., Vollertsen F. (2015). Influence of tool geometry variations on the limiting drawing ratio in micro deep drawing. Int. J. Mater. Form. 9, pp. 253-258. 